\title{
Committing to socially responsible seafood
}

Ocean science must evolve to meet social challenges in the seafood sector

By John N. Kittinger, Lydia C. L. Teh, Edward H. Allison, Nathan J. Bennett, Larry B. Crowder, Elena M. Finkbeiner, Christina Hicks, Cheryl G. Scarton, Katrina Nakamura, Yoshitaka Ota, Jhana Young, Aurora Alifano, Ashley Apel, Allison Arbib, Lori Bishop, Mariah Boyle, Andrés M. Cisneros-Montemayor, Philip Hunter, Elodie Le Cornu, Max Levine, Richard S. Jones, J. Zachary Koehn, Melissa Marschke, Julia G. Mason, Fiorenza Micheli, Loren McClenachan, Charlotte Opal, Jonathan Peacey, S. Hoyt Peckham, Eva Schemmel, Vivienne Solis- Rivera, Wilf Swartz, T. 'Aulani Wilhelm

This is a preprint version of this article, formally published in Science on 2 June 2017, Volume 356, Issue 6341, DOI: 10.1126/science.aam9969.

Seafood is the world's most internationally traded food commodity. Approximately three out of every seven people globally rely on seafood as a primary source of animal protein (1).

Revelations about slavery and labor rights abuses in fisheries have sparked out- rage and shifted the conversation $(2,3)$, placing social issues at the forefront of a sector that has spent decades working to improve environmental sustainability. In response, businesses are seeking to reduce unethical practices and reputational risks in their supply chains. Governments are formulating policy responses, and nonprofit and philanthropic organizations are deploying resources and expertise to address critical social issues. Yet the scientific community has not kept pace with concerns for social issues in the sector. As the United Nations Ocean Conference convenes in New York (5 to 9 June), we propose a framework for social responsibility and identify key steps the scientific community must take to inform policy and practice for this global challenge.

Over the past several decades, the scientific community has invested sizable effort in determining key elements for environmental sustainability in fisheries and aquaculture, informing the creation of globally recognized standards [e.g., (4)]. A similar effort is now needed for social responsibility, yet comparatively little research effort has been invested in the social dimensions of seafood sustain- ability. As a result, the seafood sector has largely been in a reactive stance, responding to visible issues associated with slavery and human rights. Although these egregious violations must be eliminated, social responsibility encompasses far more, and a narrow focus overlooks other pervasive issues that have real-world impacts on billions of people.

To remedy this, we developed a comprehensive framework for social responsibility, responding to a need for alignment around a shared, transdisciplinary approach, informed by a strong scientific basis to support policy and practice. Policy instruments such as the International Labour Organization's Work in Fishing Convention, the Food and Agriculture Organization of the United Nations' Voluntary Guidelines for Securing Small-Scale Fisheries, and the UN's guiding principles on business and human rights are already being used by governments, businesses, 
and non-profit organizations as the basis for action on specific issues, such as human rights and labor. Our framework unites a diverse set of social issues that have heretofore been fragmented and is informed by social science research on human rights, natural resource management, and international development. Our framework is also informed by practical experience from organizations and experts that work in the seafood sector and is supported by a strong legal and policy basis for implementation, as indicated by review of international law, policy, and guidance (table S1). The framework comprises three components (see fig. S1): (i) protecting hu- man rights and dignity and respecting access to resources, (ii) ensuring equality and equitable opportunities to benefit, and (iii) improving food and livelihood security (see the photo).

\section{Framing Social Responsibility}

Protecting human rights requires that fundamental human rights are respected, labor rights are protected, and decent working conditions and safety standards are pro- vided, particularly for at-risk groups. Human rights violations range in severity from the most egregious, such as slavery, to less acute but pervasive practices such as abrogation of wages, poor working conditions, and restrictions on freedoms. Violation of these rights in the seafood industry has been observed in both developing and developed economies (5). A largely overlooked, but critical, aspect of human rights is rights to re- sources, including traditional tenure and access rights. These social, economic, and cultural rights are central to many indigenous management systems and are especially relevant in small- scale and customary fisheries that supply most of the catch for direct human consumption but where regulatory institutions to protect fishers' interests are generally lacking (6).

Ensuring that seafood is equitably produced requires that benefits derived from its production accrue to all participants in the supply chain (e.g., fishers, processors, and distributors), not just those with financial or political power (7). Ensuring equality requires that workers receive appropriate recognition, voice, and engagement, irrespective of their gender, ethnicity, nationality, culture, or socioeconomic status. Marginalized groups, such as women, are often discounted in terms of their role, knowledge, or influence in fisheries (8), and the high prevalence of migrant labor in the seafood industry can create conditions ripe for discrimination (5). Failure to recognize issues of equity and social justice can result in misguided policies, often with consequences for small-scale producers, minorities, or women (9).

Improving food and livelihood security requires that ocean-dependent communities, some of the most vulnerable people in the world, do not suffer from the global seafood trade (8). In coastal fisheries in Africa, for example, extraction by foreign fleets is reducing the availability of fish, the main source of animal protein, affecting both nutritional and income security (10). Such practices place vulnerable populations at risk and run counter to the UN's Sustainable Development Goals (SDGs). Businesses are obligated under international policy to ensure that their practices do not undermine food and livelihood security, including providing fair access to markets and preserving capabilities for workers to generate income in the face of social and environmental change. Businesses can do more than mitigate their impact and should seek to 
improve livelihood conditions where they operate and ensure food security where seafood is a critical component of diets (11).

\section{Science for a Sea Change}

This framework can aid in global alignment among governments, businesses, civil society and nonprofit organizations, driving integration of social responsibility into policy, practice, and ultimately performance in the sector. Here, we identify opportunities for the scientific community to support this transition by providing relevant knowledge to inform actionable approaches toward social outcomes.

First, ocean science must evolve-incorporating a stronger focus on social dimensions and their linkages to environmental issues. Social science is embedded in sustainability science, but key social science concepts such as agency, inequality, and social justice are missing from many sustainability efforts (12), and social science research capacity in the sector is woefully inadequate. Environmental challenges -including habitat destruction, overfishing, and resource collapse-threaten the viability of livelihoods and food security and create conditions for discrimination and subversion of human rights. Social and environmental issues often overlap in the same geographies, such as Southeast Asia, a hotspot of overfishing and labor issues (13). In these areas, slavery and forced labor depress the true cost of extraction, which distorts the market and promotes overexploitation (14). The research community can play a timely and important role in assessing the linkages between environmental sustainability and social issues, bringing necessary expertise together to inform responses by businesses, government, nonprofits, and communities. The UN SDGs explicitly recognize the link between ecosystem health and human well- being, but more integrated approaches need to be developed to address these issues in the fisheries and aquaculture sector.

Second, the scientific community has a major role to play in research, monitoring, and analysis of the seafood sector, including developing rigorous, objective approaches to evaluate performance. Evidence-based assessments are needed to understand the scale of social abuses and the efficacy of approaches, particularly as governments begin to translate existing international laws, policies, and guidance (table S1) into domestic laws, regional initiatives, and regulations to improve industry practices. Social science provides a strong foundation for these approaches, and existing performance indicators and tools [e.g., $(12,15)]$ need to be adapted to meet this challenge. The research community can also integrate social responsibility indicators into globally accepted performance standards for sustainable seafood by ratings and certification schemes, reducing the prevalence of social abuses and risks for businesses. Continued development of research approaches, tools, and technologies will be critical, particularly to ensure transparency and accountability, to reduce risk and secure market incentives for businesses, and to produce credible information while considering the sensitivity and risk associated with researching these issues (13).

Third, the research community must be responsive to real-world needs. The current level of commitment to integrating the priorities of stakeholders and decision-makers into research is inadequate. This requires more than simply training and hiring more social scientists in the 
sector-it requires a shift in (i) the way social and environmental research is conceptualized and conducted together with stakeholders, (ii) the expertise prioritized in the development of research capacity and initiatives, and (iii) the level of resources directed toward these issues. This requires prioritizing the coproduction of knowledge with the scientific com- munity engaged together with stakeholders in a participatory approach to develop re- search initiatives that have a clear pathway

for implementation in practice. The ocean science community can benefit from experience in other production sectors - including agriculture, forestry, energy, and mining - that have addressed similar challenges by investing in shared strategies, a strong multidisciplinary evidence base, and collaborative institutional arrangements and global research networks [e.g., $(16,17)]$.

By 2030, the oceans will need to supply 152 to 188 million metric tons of seafood to nourish a growing population (18). Fulfilling this demand in a socially and environmentally sustainable manner will require increased investment from public and private sources, so that the level of resources and expertise committed is commensurate with the scale of these challenges. Across the sector, organizations that work on environmental sustain- ability issues will need to work more closely with socially focused organizations, as these issues are intrinsically linked and require joint investments. The global conversation about social issues presents an opportunity for the seafood sector to take steps to ensure that a healthy ocean will support human wellbeing, now and into the future.

\section{References and Notes}

1. Food and Agricultural Organization of the United Nations, "The state of world fisheries and aquaculture" (FAO, 2016).

2. K. Hodal, C. Kelly, F. Lawrence, Guardian, 10 June 2014.

3. M. Mendoza, R. McDowell, M.Mason, E. Htusan, “Fishermen slaves: Human trafficking and the seafood we eat" (Associated Press, 15 March 2016).

4. Marine Stewardship Council, "MSC fisheries standard” (MSC, London, 2014).

5. M. Marschke, P. Vandergeest, Mar. Policy 68, 39 (2016).

6. C. Sharma, Mar. Stud. 10, 41 (2011).

7. C. Béné, R. Lawton, E. H. Allison, World Dev. 38, 933 (2010).

8. N. Weeratunge, K. A. Snyder, C. P. Sze, Fish Fish.11,405 (2010).

9. E. H. Allison, F. Ellis, Mar. Policy 25, 377 (2001).

10. J. S. Brashares et al., Science 306, 1180 (2004).

11. C. D. Golden et al., Nature 534, 317 (2016).

12. C. C. Hicks et al., Science 352, 38 (2016).

13. J. Stride, D. Murphy, "Assessing government and business responses to the Thai seafood crisis" (The Freedom Fund, London, and Humanity United, San Francisco, CA, 2016); http://freedomfund.org/wp-content/uploads/Thai- seafood-reforms-FINAL.pdf.

14. S. Gold, A. Trautrims, Z. Trodd, Supply Chain Manag .Int .J. 20, 485 (2015).

15. J. L. Anderson et al., PLOS ONE 10, e0122809 (2015). 
16. Humanity United, Free and Fair Labor in Palm Oil Production: Principles and Implementation Guidance (Humanity United, San Francisco, CA, 2015).

17. Sustainable Coffee Challenge, "Sustainability Framework" (Conservation International, 2016)

18. Secretariat, Fishing for a Future, Getting to Eden: Building an Ideal Future for the Global Fish Food System through Collective Action (Fishing for a Future, 2013).

\section{Acknowledgements}

The opinions expressed in this article are the authors' own and do not reflect the institutional policies or viewpoints of organizations with which individual authors are affiliated. We acknowledge support from the Nippon Foundation's Nereus Program, the NSF IGERT Program on Ocean Change (award no. 1068839), the Center for Ocean Solutions, Stanford University, the Social Sciences and Humanities Research Council of Canada, and the Liber Ero Fellowship Program.

\section{Supplementary Text}

John N. Kittinger, ${ }^{1,2,3^{*}}$ Lydia C. L. Teh, ${ }^{4}$ Edward H. Allison, ${ }^{5}$ Nathan J. Bennett, $, 6,7$ Larry B. Crowder, ${ }^{7,8}$ Elena M. Finkbeiner, ${ }^{7}$ Christina Hicks, ${ }^{9}$ Cheryl G. Scarton, ${ }^{10}$ Katrina Nakamura, ${ }^{11}$ Yoshitaka Ota, ${ }^{4,5}$ Jhana Young, ${ }^{1}$ Aurora Alifano, ${ }^{12}$ Ashley Apel, ${ }^{13}$ Allison Arbib, ${ }^{14}$ Lori Bishop, ${ }^{15}$ Mariah Boyle, ${ }^{10}$ Andrés M. Cisneros-Montemayor, ${ }^{3}$ Philip Hunter, ${ }^{12}$ Elodie Le Cornu, ${ }^{6}$ Max Levine, ${ }^{16}$ Richard S. Jones, ${ }^{17} \mathrm{~J}$. Zachary Koehn, ${ }^{18}$ Melissa Marschke, ${ }^{19}$ Julia G. Mason, ${ }^{8}$ Fiorenza Micheli, ${ }^{7,8}$ Loren McClenachan, ${ }^{20}$ Charlotte Opal, ${ }^{13}$ Jonathan Peacey, ${ }^{1}$ S. Hoyt Peckham, ${ }^{7,21}$ Eva Schemmel, ${ }^{1}$ Vivienne Solis-Rivera, ${ }^{22}$ Wilf Swartz, ${ }^{23}$ T. 'Aulani Wilhelm ${ }^{1}$

1. Center for Oceans, Conservation International, Honolulu, HI 96825, USA.

2. Betty and Gordon Moore Center for Science, Conservation International, Arlington, VA 22202, USA.

3. Center for Biodiversity Outcomes, Julie Ann Wrigley Global Institute of Sustainability, Arizona State University, Tempe, AZ 85281, USA.

4. Nereus Program, Institute for the Oceans and Fisheries, University of British Columbia, Vancouver V6T1Z4 Canada.

5. School for Marine and Environmental Affairs, University of Washington, Seattle, WA 98105, USA.

6. Institute for Resources, Environment and Sustainability, University of British Columbia, Vancouver, British Columbia, V6T1Z4 Canada.

7. Center for Ocean Solutions, Stanford University, Stanford Woods Institute for the Environment, Monterey, CA 93940, USA.

8. Hopkins Marine Station, Stanford University, Pacific Grove, CA 93950, USA.

9. Lancaster Environment Centre, Lancaster University, Lancaster, LA1 4YQ, UK.

10. University of Hawai'i at Mānoa, Honolulu, HI 96822, USA.

11. The Sustainability Incubator, Honolulu, HI 96821, USA.

12. FishWise, Santa Cruz, CA, 95061, USA.

13. Fair Trade USA, Oakland, CA 94612, USA. 
14. Verité, Amherst, MA 01002, USA.

15. Lori Bishop Consulting, San Luis Obispo, CA 93405, USA.

16. California Environmental Associates, San Francisco, CA 94111, USA.

17. Ocean Outcomes, Portland, OR 97204, USA.

18. School of Aquatic and Fishery Sciences, University of Washington, Seattle, WA 98105, USA.

19. School of International Development and Global Studies, University of Ottawa, Ottawa K1N6N5 Canada

20. Colby College, Waterville, ME 04901, USA.

21. Smartfish AC, 2395 Marquez de León, La Paz, México 23000.

22. Coope Sol i Dar R.L, San José, Costa Rica.

23. Ocean Policy Research Institute, Sasakawa Peace Foundation, Tokyo, Japan.

*Corresponding author. Email: jkittinger@gmail.com 
Figure S1. Three essential components of socially responsible seafood, derived from relevant research, policy and practice.

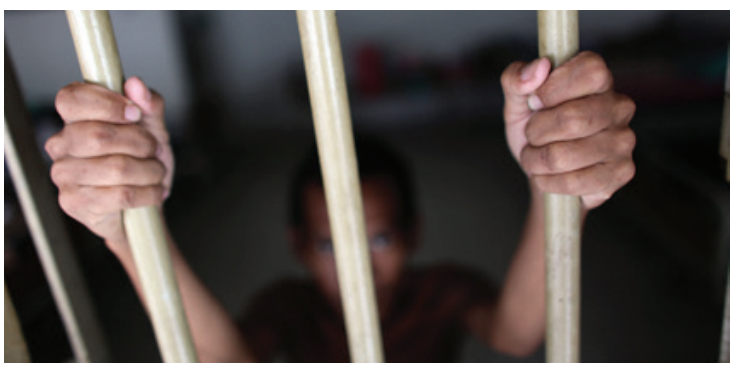

PROTECT HUMAN RIGHTS, DIGNITY, AND ACCESS TO RESOURCES

- Basic human rights and dignity are respected, labor rights are protected, and adequate living and working conditions provided

- Rights to resources, including tenure and access rights, are secured

() Josh Estey/Flickr Creative Commons

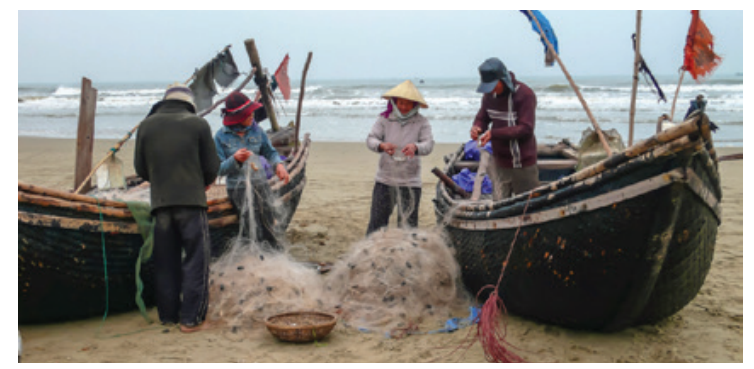

ENSURE EQUALITY AND EQUITABLE OPPORTUNITY TO BENEFIT

- Equal opportunities to benefit are ensured to all workers

- Recognitions (standing), voice, and respectful engagement for all groups, irrespective of gender, ethnicity, culture, or socioeconomic status

(c) Lain/Flickr Creative Commons

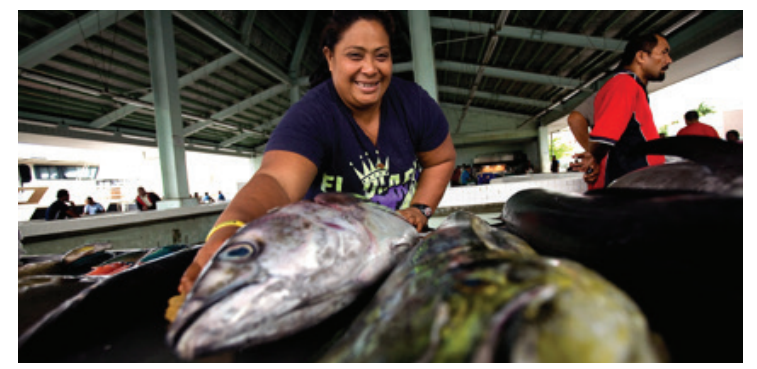

IMPROVE FOOD AND LIVELIHOOD SECURITY

- Nutritional and sustenance needs of resource-dependent communities are maintained or improved

- Livelihood opportunities are secured or improved, including fair access to markets and capabilities to maintain income generation

Photo: (C) Asian Development Bank/Flickr Creative Commons 
Table S1. Relevant international and multi-lateral laws, policies and guidance documents, which provide the legal and policy bases for implementing the essential components of socially responsible seafood.

\begin{tabular}{|c|c|}
\hline Social Principle & Relevant International and Multi-Lateral Laws, Policies, and Guidance \\
\hline $\begin{array}{l}\text { Protect human rights, } \\
\text { dignity, and access to } \\
\text { resources }\end{array}$ & $\begin{array}{l}\text { FAO Code of Conduct for Responsible Fisheries, } 1995 \\
\text { FAO Voluntary Guidelines on the Responsible Governance of Tenure of Land, Fisheries and Foresets in the Context of National Food Security, } 2012 \\
\text { ILO Abolition of Forced Labour Convention, } 1957 \text { (No. 105) } \\
\text { ILO Work in Fishing Convention, } 2007 \text { (No. 188) } \\
\text { ILO Worst Forms of Child Labour Convention, } 1999 \text { (No. 182) } \\
\text { International Covenant on Civil and Political Rights, } 1966 \\
\text { International Covenant on Economic, Social and Cultural Rights, } 1966 \\
\text { UN Convention on the Rights of the Child, } 1989 \\
\text { UN Declaration on the Rights of Indigenous Peoples, } 2007 \\
\text { UN Guiding Principles on Business and Human Rights, } 2011 \\
\text { UN Protocol to Prevent, Suppress and Punish Trafficking in Persons Especially Women and Children, } 2000 \\
\text { UN Universal Declaration of Human Rights, } 1948\end{array}$ \\
\hline $\begin{array}{c}\text { Ensure equality and } \\
\text { equitable } \\
\text { opportunities to } \\
\text { benefit }\end{array}$ & $\begin{array}{l}\text { FAO Port State Measures Agreement, } 2009 \\
\text { FAO Voluntary guidelines for securing sustainable small-scale fisheries in the context of food security and poverty eradication, } 2015 \\
\text { RFMO Trade and Catch Documentation Schemes and Trade Restrictive Measures } \\
\text { UN Convention on the Elimination of All Forms of Discrimination against Women, } 1979 \\
\text { UN Declaration on the Rights of Persons Belonging to National or Ethnic, Religious, and Linguistic Minorities, } 1992 \\
\text { UNECE Aarhus Convention on Access to Information, Public Participation in Decision-Making and Access to Justice in Environmental Matters, } 1998 \\
\text { UNESCO Universal Declaration on Cultural Diversity, } 2001\end{array}$ \\
\hline $\begin{array}{l}\text { Improve food and } \\
\text { livelihood security }\end{array}$ & $\begin{array}{l}\text { FAO \& WHO Rome Declaration on Nutrition, } 2014 \\
\text { FAO An Introduction to the Basic Concepts of Food Security, } 2008 \\
\text { FAO International Plan of Action to prevent, deter and eliminate illegal, unreported and unregulated fishing, } 2001 \\
\text { FAO Port State Measures Agreement, } 2009 \\
\text { FAO Voluntary guidelines for securing sustainable small-scale fisheries in the context of food security and poverty eradication, } 2015 \\
\text { FAO Voluntary guidelines on the responsible governance of tenure of land, fisheries and forests in the context of national food security, } 2012 \\
\text { FAO Voluntary guidelines to support the progressive realization of the right to adequate food in the context of national food security, } 2004 \\
\text { FAO Policy Guidance Note: Strengthening sector policies for better food security and nutrition results, } 2017 \\
\text { International Covenant on Economic, Social and Cultural Rights, } 1966 \\
\text { UN Declaration on the Right to Development, } 1986\end{array}$ \\
\hline
\end{tabular}




\section{REFERENCES AND NOTES}

1. Food and Agricultural Organization of the United Nations, "The state of world fisheries and aquaculture" (FAO, 2016).

2. K. Hodal, C. Kelly, F. Lawrence, The Guardian, 10 June 2014.

3. M. Mendoza, R. McDowell, M. Mason, E. Htusan, M. Mendoza, R. McDowell, M. Mason, E. Htusan, "Fishermen slaves: Human trafficking and the seafood we eat" (Associated Press, 15 March 2016).

4. Marine Stewardship Council, "MSC fisheries standard” (MSC, London, 2014).

5. M. Marschke, P. Vandergeest, Mar. Policy 68, 39 (2016). doi:10.1016/j.marpol.2016.02.009

6. C. Sharma, Mar. Stud. 10, 41 (2011).

7. C. Béné, R. Lawton, E. H. Allison, World Dev. 38, 933 (2010). doi:10.1016/j.worlddev.2009.12.010

8. N. Weeratunge, K. A. Snyder, C. P. Sze, Fish Fish. 11, 405 (2010). doi:10.1111/j.14672979.2010.00368.x

9. E. H. Allison, F. Ellis, Mar. Policy 25, 377 (2001). doi:10.1016/S0308-597X(01)00023-9

10. J. S. Brashares et al., Science 306, 1180 (2004). doi:10.1126/science.1102425

11. C. D. Golden et al., Nature 534, 317 (2016). doi:10.1038/534317a

12. C. C. Hicks et al., Science 352, 38 (2016). doi:10.1126/science.aad4977

13. J. Stride, D. Murphy, "Assessing government and business responses to the Thai seafood crisis" (The Freedom Fund, London, and Humanity United, San Francisco, CA, 2016); http://freedomfund.org/wp-content/uploads/Thai-seafood-reforms-FINAL.pdf.

14. S. Gold, A. Trautrims, Z. Trodd, Supply Chain Manag. Int. J. 20, 485 (2015). doi:10.1108/SCM-02-2015-0046

15. J. L. Anderson et al., PLOS ONE 10, e0122809 (2015). doi:10.1371/journal.pone.0122809

16 Humanity United, Free and Fair Labor in Palm Oil Production: Principles and Implementation Guidance (Humanity United, San Francisco, CA, 2015).

17. Sustainable Coffee Challenge, "Sustainability Framework" (Conservation International, 2016)

18. Secretariat, Fishing for a Future, Getting to Eden: Building an Ideal Future for the Global Fish Food System Through Collective Action (Fishing for a Future, 2013). 